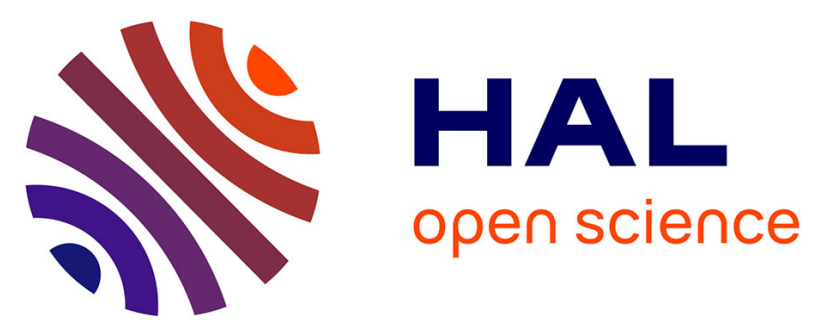

\title{
Fabrication of ultra-sharp tips from carbon fiber for scanning tunneling microscopy investigations of epitaxial graphene on $6 \mathrm{H}-\mathrm{SiC}(0001)$ surface
}

José A. Morán-Meza, Christophe Lubin, François Thoyer, Kevin A. Villegas-Rosales, Abel A. Gutarra-Espinoza, Frantz Martin, Jacques Cousty

\section{To cite this version:}

José A. Morán-Meza, Christophe Lubin, François Thoyer, Kevin A. Villegas-Rosales, Abel A. GutarraEspinoza, et al.. Fabrication of ultra-sharp tips from carbon fiber for scanning tunneling microscopy investigations of epitaxial graphene on $6 \mathrm{H}-\mathrm{SiC}(0001)$ surface. Carbon, 2015, 86, pp.363-370. 10.1016/j.carbon.2015.01.050 . cea-01273486

\section{HAL Id: cea-01273486 https://hal-cea.archives-ouvertes.fr/cea-01273486}

Submitted on 12 Feb 2016

HAL is a multi-disciplinary open access archive for the deposit and dissemination of scientific research documents, whether they are published or not. The documents may come from teaching and research institutions in France or abroad, or from public or private research centers.
L'archive ouverte pluridisciplinaire HAL, est destinée au dépôt et à la diffusion de documents scientifiques de niveau recherche, publiés ou non, émanant des établissements d'enseignement et de recherche français ou étrangers, des laboratoires publics ou privés. 


\title{
Fabrication of ultra-sharp tips from carbon fiber for scanning tunneling microscopy investigations of epitaxial graphene on $6 \mathrm{H}-\mathrm{SiC}(0001)$ surface
}

\author{
J.A. Morán Meza ${ }^{a, b, *}$, C. Lubin ${ }^{a}$, F. Thoyer ${ }^{a}$, K.A. Villegas Rosales ${ }^{b}$, \\ A.A. Gutarra Espinoza ${ }^{b}$, F. Martin ${ }^{c}$, J. Cousty ${ }^{a, *}$ \\ a Service de Physique de l'Etat Condensé, DSM/IRAMIS/SPEC, CNRS UMR 3680, CEA Saclay, 91191 Gif sur Yvette Cedex, France \\ ${ }^{\mathrm{b}}$ Grupo de Materiales Nanoestructurados, Facultad de Ciencias, Universidad Nacional de Ingeniería, Av. Túpac Amaru 210, Lima 25, Peru \\ ${ }^{c}$ Laboratoire d'Etude de la Corrosion Aqueuse, SCCME, DPC, DEN, CEA Saclay, 91191 Gif sur Yvette Cedex, France
}

\section{A R T I C L E I N F O}

Article history:

Received 6 October 2014

Accepted 26 January 2015

Available online 3 February 2015

\begin{abstract}
A B S T R A C T
The fabrication of ultra-sharp tips from carbon fiber (CF), which are mounted on a qPlus probe for combined dynamic scanning tunneling microscopy (STM) and frequency modulation atomic force microscopy (FM-AFM) experiments, is reported. The carbon fiber tips were electrochemically etched in a $\mathrm{KOH}$ or $\mathrm{NaOH}$ solution, using different electronic devices. CF tips with an apex radius $\sim 10 \mathrm{~nm}$, as deduced from the measured slopes of the Fowler-Nordheim plots ( $k \mathrm{R}<70 \mathrm{~nm}$ for $k \sim 6$ ), were routinely obtained with a homemade electronic device that controls the intensity of the etching current. Then, these conductive CF tips were also characterized by imaging the $6 \mathrm{H}-\mathrm{SiC}(0001)$ surface covered by an epitaxial graphene layer in ultra-high vacuum (UHV). The lattice of the $(6 \sqrt{3} \times 6 \sqrt{3}) \mathrm{R} 30^{\circ}$ reconstruction was regularly imaged by STM working either in non-oscillating mode or in dynamic mode, which also maps the variations of the force gradient. From these measurements with a constant mean-tunneling-current of $20 \mathrm{pA}$, it was found that the STM tip suffered variations of the tip/surface force gradient in between 8.25 and $16.50 \mathrm{~N} / \mathrm{m}$ when it scanned the epitaxial graphene layer on the reconstructed $6 \mathrm{H}-\mathrm{SiC}(0001)$ surface.
\end{abstract}

(c) 2015 Elsevier Ltd. All rights reserved.

\section{Introduction}

Nowadays many properties of solid matter, at the nanoscale, are being studied in the real space using atomic force microscopy (AFM) [1] or scanning tunneling microscopy (STM) [2] for conductive samples. In both techniques, sharp tips are required to explore surface properties down to the atomic scale. Tremendous efforts have been devoted to improve the tip sharpness since the first STM studies [3-13] because the shape of the tip apex and its chemical and physical properties determine the resolution achieved in the images. For AFM based on optical detection, commercially available cantilevers make these investigations easier because they present microfabricated tips with a relatively well controlled shape. Recently, a new kind of AFM based on a quartz resonator was developed [14-16]. These microscopes are based on a piezoelectric force sensor called qPlus. This sensor is based on a quartz tuning fork which one of the prongs is fixed to a support, while the

\footnotetext{
* Corresponding authors at: Service de Physique de l'Etat Condensé, DSM/IRAMIS/SPEC, CNRS UMR 3680, CEA Saclay, 91191 Gif sur Yvette Cedex, France.

E-mail addresses: jmoranm@uni.edu.pe (J.A. Morán Meza), jacques.cousty@cea.fr (J. Cousty). http://dx.doi.org/10.1016/j.carbon.2015.01.050
} 0008-6223/@ 2015 Elsevier Ltd. All rights reserved. 
tip is glued on the end of the free prong [16]. Because these qPlus sensors are stiffer $(500<k<15000 \mathrm{~N} / \mathrm{m})$ than conventional microfabricated cantilevers $(k<40 \mathrm{~N} / \mathrm{m})$, the tip can approach to the surface without the jump-to-contact. As a consequence, the tip can oscillate with a small oscillation amplitude (few ångströms to sub-ångström) and within a small distance above the surface [17]. Considering this small tip/ sample distance, the tuning fork force sensor equipped with a conductive tip becomes capable of simultaneously obtain information of the force gradient and the mean-tunneling-current between the tip and conductive sample. Such a combined STM/AFM mode paves the way for the exploration of local surface properties $[18,19]$. However, the material of the tip has to be carefully selected to ensure an optimal operation when working in both STM and AFM modes. Tungsten and platinum/iridium (Pt/Ir), which are the most commonly metals used for fabricating STM tips, present some drawbacks when fixed on the tuning fork for combined STM/AFM. First, the mass of such metallic tips glued to one prong, of the tuning fork, causes a decrease of the quality factor value that reduces the force gradient sensitivity of the probe [20]. The other drawback is that these metals are often covered by a layer of insulating compounds after the electrochemical etching of the tip. These overlayers could be thick enough for hindering the electron tunneling process between the tip and surface [9]. In conventional STM experiments in UHV, this overlayer is generally removed by different treatments such as resistive heating for $\mathrm{W}$ tips [13], or by ion sputtering treatment for $\mathrm{W}$ and Pt tips [21]. But cleaning the tip becomes a real challenge for a small piece of $\mathrm{W}$ or $\mathrm{Pt} / \mathrm{Ir}$ wire attached at the free end of a tuning fork prong. Heating is forbidden because of the glue, and the ion beam must be well focused for sputtering the tip and not the electrodes of the tuning fork. In that context, tips based on carbon materials appear as promising probes for combined STM/ AFM based on a quartz tuning fork. Some carbon-based tips were built from amorphous carbon generated from an electron beam [22,23], and more recently by attaching a carbon nanotube at the end of conventional tips [24-27]. Carbon fibers (CFs) were also used to fabricate nanometer sized tips at their ends [28-37]. Mainly etched by electrochemical procedures, the apex shape of these ultramicroelectrodes fashioned from CF, was generally studied by scanning electron microscopy (SEM). However Mousa investigated the field electron emission (FEE) properties of electrochemically etched carbon fiber tips, and found that the tip apex radius was below $100 \mathrm{~nm}$ [29]. Despite their chemical stability and electrical properties, there are few examples of carbon fiber tips used as STM and/or AFM probe which have been reported in the literature [32-37]. Recently, Castellanos Gomez et al. [32,34,35] presented results obtained with carbon fiber tips in an AFM/STM system. Atomic resolution was achieved on a freshly cleaved surface of highly oriented pyrolytic graphite in constant height STM mode. Schulte et al. have fabricated well-formed nanocones, at the end of a CF, for miniaturized voltammetric sensors [30]. Used as STM probes, such CF tips achieved atomic resolution on a clean Si(111) surface in UHV [33].

In this paper, we present the study of the fabrication and characterization of nanometer sized tips made from commercial carbon fibers. The fibers were first etched by a controlled electrochemical process. Then SEM and FEE, through Fowler-
Nordheim (F-N) plots [38], were used to characterize the geometry of the apex of the tips. These CF tips fixed on a quartz tuning fork, working in a qPlus configuration, are the probes of a combined AFM/STM in UHV at room temperature. In order to check their sharpness, the structure of an epitaxial graphene layer thermally grown on top of a $6 \mathrm{H}-\mathrm{SiC}(0001)$ surface was explored.

\section{Experimental}

The tips were electrochemically etched from $6.7 \mu \mathrm{m}$-diameter carbon fibers (CF) (polyacrylonitrile-type, Hexcel ${ }^{\circledR}$ HexForce $^{\circledR}$ G0986 D1200) which were ultrasonically cleaned in ethanol, before the process. The electrochemical cell was formed by the CF placed at the center of a Pt ring (Outer diameter $\sim 4 \mathrm{~mm}$, wire diameter $0.25 \mathrm{~mm}$ ) as counter electrode. The fiber is vertically immersed into a drop of the etchant solution, which is suspended by the ring (Fig. 1). Two electronic

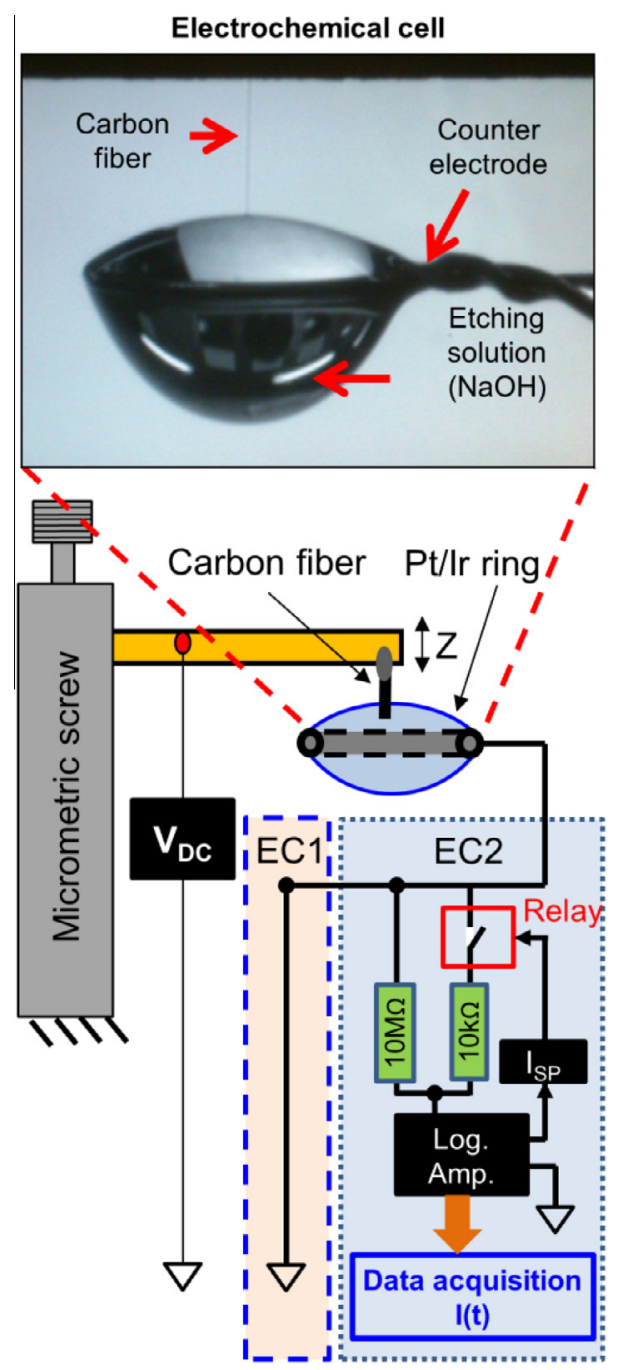

Fig. 1 - Schematic view of the electrochemical cell and electronic circuits for electrochemical etching of carbon fiber. EC1 branch was first used in the Lima Lab while the EC2 one was built and used in the CEA Lab. Photo (close view of the tip etched in the droplet). (A color version of this figure can be viewed online.) 
devices were used for the process. In the first set up (EC1 in Fig. 1), installed in Lima Lab (Peru), a constant DC voltage was applied from a potentiostat (Model 263A Princeton instruments) on to the cell during the whole process. At the end, the current drops down to zero when the tip was detached from the etchant solution. In the other set up (EC2 in Fig. 1), established in Saclay Lab (France), the cell is connected to a DC power supply and to a homemade electronic device. In contrast with the EC1 circuit, the EC2 set up limits to the etching current intensity in the final stage of the tip formation. This homemade device allowed us to measure the etching current and to drastically reduce the etching current at a pre-selected current value. The device is based on a logarithmic amplifier that through a relay, adds a $10 \mathrm{M} \Omega$ resistance into the electric circuit when the electrochemical current intensity reaches a preset value (Fig. 1 part EC2). As a result, the etching rate during the final stage of the tip apex formation is strongly reduced. At the end of both etching processes (EC1 and EC2), the tips were ultrasonically cleaned in Milli-Q water bath at $80^{\circ} \mathrm{C}$, rinsed in ethanol and finally dried in an oven at $120^{\circ} \mathrm{C}$ for $5-10 \mathrm{~min}$.

To characterize the tip geometry a SEM (JEOL JSM 5510 LV with a $10 \mathrm{~nm}$ resolution), a FEE (through F-N plots) and STM/ AFM exploration were used. For measuring the electronic current resulting from a high electric field applied to its apex, a small UHV chamber connected to a turbomolecular pump (Turbo-V 70LP pump, Varian) and an oil-free diaphragm pump (Varian MDP12) was built. The pumps ensured a base pressure lower than $10^{-7}$ mbar in $1 \mathrm{~h}$. A linear motion feedthrough equipped with a high voltage electrical feedthrough supports a gold-covered counter electrode in front of the tip. The distance between the tip apex and the counter electrode was adjusted to $0.5 \mathrm{~mm}$. A high voltage power supply (Bertan Series 225) generated a tension up to $3 \mathrm{kV}$. A homemade device based on a logarithmic operational amplifier (TI Log101) was used to measure the electronic current in a large range from $0.1 \mathrm{nA}$ up to $100 \mu \mathrm{A}$. Typically, the onset of the electronic current due to field emission from the sharp CF tip was detected for an applied voltage of typically $150-300 \mathrm{~V}$ which, indeed, provides rough information of the tip sharpness. For a more precise characterization of the tip geometry the emission current (I) was measured as a function of the applied voltage (V). In the F-N regime, I varies as shown by the equation [39] (using the approximation of Spindt et al. [40]):

$\mathrm{I}=\mathrm{A}\left(\mathrm{F}^{2} / \phi\right) \exp \left(9.84 / \phi^{1 / 2}\right) \exp \left(-6.49 \times 10^{9} \phi^{3 / 2} / F\right)$

where $A$ is a constant, $\phi$ the local work function of the material of the tip in $\mathrm{eV}, \mathrm{F}$ is the local electric field related to the applied voltage $\mathrm{V}$ via $\mathrm{F}=\beta \mathrm{V}$, with $\beta=1 / \mathrm{kR}$ being the field conversion factor, $R$ is the curvature radius of the tip apex and $k$ is the field reduction factor. The value of $k$ depends on the exact tip geometry and the distance between the tip apex and the counter electrode [41,42], its value varies between 3 and 35 in the case of tungsten tips $[13,43,44]$. Dividing the Eq. (1) by $\mathrm{V}^{2}$ and taking the nature logarithm on both sides, we obtain: $\operatorname{Ln}\left(\mathrm{I} / \mathrm{V}^{2}\right)=\operatorname{Ln}\left(\mathrm{A} \beta^{2} / \phi\right)+9.84 / \phi^{1 / 2}-\left(6.49 \times 10^{9} \phi^{3 / 2} / \beta\right)(1 / \mathrm{V})$

From the slope ' $m$ ' of the linear variation of the F-N plot $\operatorname{Ln}\left(\mathrm{I} / \mathrm{V}^{2}\right)$ vs $1 / \mathrm{V}$, we can obtain
$\mathrm{kR}=-m / 6.49 \times 10^{9} \phi^{3 / 2}$

With $\phi_{\text {Carbon }}=\phi_{\text {Graphite }}=4.8 \mathrm{eV} \mathrm{[45]} \mathrm{and} \mathrm{a} \mathrm{model} \mathrm{of} \mathrm{the} \mathrm{tip}$ geometry for estimating $\mathrm{k}$, the value of $\mathrm{R}$ can be deduced. Selected CF tips were attached with conductive glue (H21D Epotek, Epoxy Technology, USA) onto a quartz tuning fork (CITIZEN AMERICA CFS206-32.768-KDZF-UB) fixed to a Macor support (qPlus configuration) of an Omicron tripod holder. This operation was made under a stereo microscope (Carls Zeiss 1960s) in order to fix the CF at the end of the free prong. After curing the glue $\left(120^{\circ} \mathrm{C}\right.$ during $\left.1 \mathrm{~h}\right)$ the qPlus probe was introduced into the UHV chamber of the STM/AFM.

The combined STM/AFM system at room temperature was previously described in [19]. Briefly, it consists in a modified VT Omicron microscope (Omicron Nanotechnology) coupled to a homemade dual preamplifier connected to a controller (NANONIS-SPECS). The oscillation of the CF tip, fixed on the free prong of a qPlus probe, was set to typically $(0.1-0.2) \mathrm{nm}$ in amplitude while its resonance frequency falls in the 31$32 \mathrm{kHz}$ range. The scanning probe microscope can work in two modes based on distance regulation. In the first mode, the $Z$ distance between the non-oscillating tip and the sample was regulated by keeping the intensity of the tunneling current constant (Static STM mode or standard STM operation). In the second mode also called dynamic STM mode, the mean intensity of the tunneling current established between the oscillating tip and the sample was kept constant by adjusting the $Z$ distance. As calculated by Giessibl [17], the mean intensity of the tunneling current depends on the oscillating amplitude. Dynamic STM topography images were obtained simultaneously with maps of the variation of the resonance frequency shift which is sensitive to the force gradients between the tip apex and the surface. The WSxM software from Nanotec [46] was used for processing the images.

The $6 \mathrm{H}-\mathrm{SiC}(0001)$ samples from NovaSiC were first ex situ chemically cleaned including trichloroethylene, acetone, and methanol in an ultrasonic bath. Then the sample was immediately introduced into an UHV chamber and treated in situ by resistive heating. After degassing for $8 \mathrm{~h}$ at $600^{\circ} \mathrm{C}$, the sample was annealed for $5 \mathrm{~min}$ at different temperature between $800{ }^{\circ} \mathrm{C}$ and $1300^{\circ} \mathrm{C}$ by steps of $50^{\circ} \mathrm{C}$ under a base pressure lower than $10^{-9} \mathrm{mbar}$ [47]. The $6 \mathrm{H}-\mathrm{SiC}(0001)$ samples covered by an epitaxial layer of graphene were transferred in air to the STM/AFM chamber. Once in the UHV chamber $\left(P=5 \times 10^{-10} \mathrm{mbar}\right)$ of the AFM/STM microscope, the samples were heated at $500-600^{\circ} \mathrm{C}$ (measured with a Pyrometer Raytek MA2S, emissivity for SiC: 0.63 ) for $1 \mathrm{~h}$ to remove contamination induced by atmosphere exposition and cooled for $2 \mathrm{~h}$ down to room temperature before STM observation.

\section{Results and discussion}

A series of CF tips were fabricated under various experimental conditions with EC1. The etchant solutions, made of $\mathrm{KOH}$, had a range of molarity from $0.2 \mathrm{M}$ up to $20 \mathrm{M}$, and the applied voltage was varied from $2 \mathrm{~V}$ up to $5 \mathrm{~V}$. From more than 50 fabricated tips, the optimized etching conditions were: $0.5 \mathrm{M}$ $\mathrm{KOH}$ solution with an applied DC voltage of $2.25 \mathrm{~V}$. Those parameters produce sharp tips. The tips were observed with an optical microscope (pictures not shown here). The etching 
time was found to depend drastically on the immersion depth; with an immersion depth of $500 \mu \mathrm{m}$ the etching time varies between 5 and $7 \mathrm{~min}$. From this first set, some CF tips observed by SEM exhibit a conical apex with a rather smooth surface and a measured apex radii equal to $\sim 50 \mathrm{~nm}$ (results not shown). In a second step, we used the EC2 electronic device that drastically reduces the etching current intensity when it takes a preset value. With a $0.5 \mathrm{M} \mathrm{NaOH}$ solution and an applied DC voltage of $2.5 \mathrm{~V}$, a typical variation of the intensity of the etching current plotted as a function of time is shown in Fig. 2. After a fast decrease of the intensity (21$8 \mu \mathrm{A})$ in the first second, the current gently decreases down to $1 \mu \mathrm{A}$ (preset value) before it drops down quickly. When the etching current took the value of $1 \mu \mathrm{A}$, the device, through a relay, automatically adds a $10 \mathrm{M} \Omega$ resistance into the circuit to decrease the etching current down to $50 \pm 30 \mathrm{nA}$ for slowing the tip etching rate. In these conditions, the etching current remained nearly constant before it drops down to zero, when the etchant solution detached from the immersed tip of CF.

Fig. 3 presents SEM micrographs of typical CF tips obtained by the EC2 device. The measured radius of the tip apex was $\sim$ $22 \pm 4 \mathrm{~nm}$. In order to get another method to determine the tip radius, we have used Fowler-Nordheim plots.

For tips fabricated with EC1 and EC2, these plots shown in Fig. 4 displayed a linear variation, with slopes which yield the $\mathrm{kR}$ product. The $\mathrm{kR}$ values ranged from 52 to $91 \mathrm{~nm}$ with the EC2 device and $\mathrm{kR}=99 \mathrm{~nm}$ with the EC1 one. We stress that the measured current intensity was limited to $\sim 1 \mu \mathrm{A}$ in order to prevent any damage caused by a heating effect at the tip apex. However the value of $\mathrm{k}$ depends on the exact tip geometry and the distance ' $d$ ' between the tip apex and the counter electrode [41,42]. For a tip modeled as a hyperboloid [41], the expression for $k$ is: $k=0.5 \operatorname{Ln}(4 d / R)$.

where $R$ is the curvature radius of the tip. With the value $\mathrm{kR}=\sigma$ known, we resolve the nonlinear equation to obtain an estimate value for ' $k$ ':

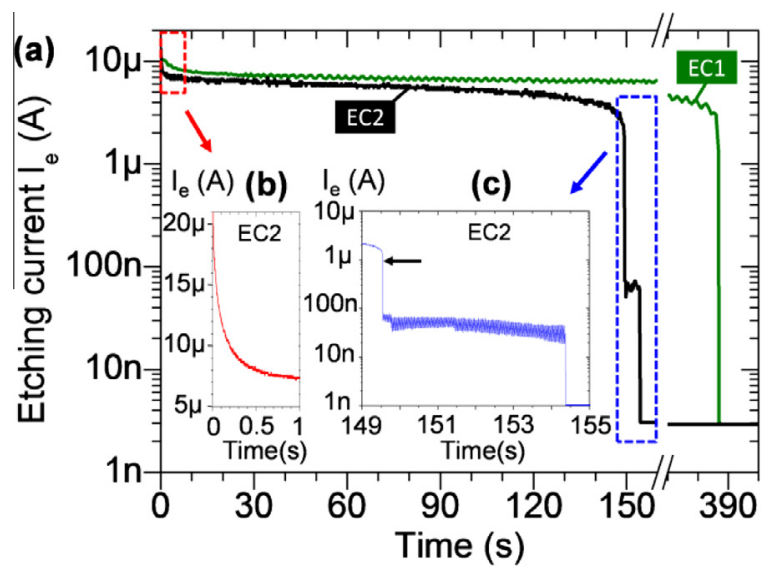

Fig. 2 - Time evolution of the etching current to the beginning (red curve) and end (blue curve) of etching electrochemical process. At the black arrow in 'c', a $10 \mathrm{M} \Omega$ resistance was added in the circuit for decreasing electrochemical current intensity and then the etching rate. (A color version of this figure can be viewed online.)
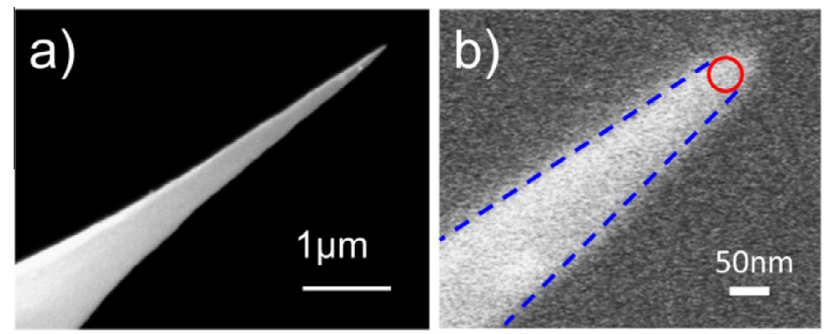

Fig. 3 - SEM micrographs of the apex of a typical CF tip made with the EC2 device: (a) micrograph shows the cone. (b) micrograph reveals the tip apex shape at high resolution. The red circle has a $22 \pm \mathbf{n m}$ radius. (A color version of this figure can be viewed online.)

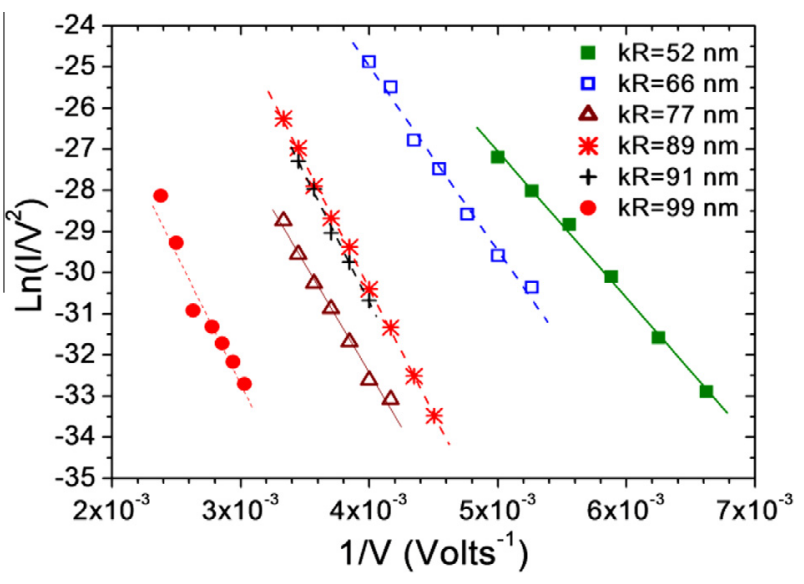

Fig. 4 - Fowler Nordheim plots of several tips fabricated with the EC2 circuit. (A color version of this figure can be viewed online.)

$k-(\sigma / 4 d) \exp (2 k)=0$

with $d=0.5 \mathrm{~mm}$ and $\mathrm{kR}$ values of 52, 66, 77, 89, 91 (for tips obtained with the EC2 device) and $99 \mathrm{~nm}$ (for a tip obtained with the EC1 device), we obtain $k$ values of $6.2,6.1,6.0,5.9$, 5.9 and 5.8, respectively. Such a value of $k=6.0 \pm 0.2$ is close to $k=5$ chosen as an adequate value by Dyke \& Dolan [41], Gomer [42] and Lucier et al. [43,44] for most geometries encountered in practice. Such a value of $\mathrm{k}$ yields also a radius consistent with the measured one in the high resolution SEM micrograph in Fig. 3.

With $k=6$, the electrochemically etched CF tips had curvature radii between 8 and $16 \mathrm{~nm}$. The best CF tips were routinely etched with the EC2 device. As a result, the tip of each etched CF was characterized by a Fowler-Nordheim plot and only the ones with $R<14 \mathrm{~nm}$ were glued onto a qPlus probe. As shown in the Appendix, the free length of the glued CF, was adjusted to be below $0.5 \mathrm{~mm}$ to prevent coupled resonance of the CF tip with the oscillating quartz sensor.

Such a sharp CF tip equipped on a qPlus probe were tested in imaging the surface of epitaxial graphene on $6 \mathrm{H}-\mathrm{SiC}(0001)$ in UHV. First, STM images were obtained with a tip attached onto a non-oscillating tuning fork, for scanning the surface. Fig. 5 shows typical constant current STM images obtained with a bias voltage of $\mathrm{V}_{\mathrm{b}}=-50 \mathrm{mV}$. In Fig. $5 \mathrm{a}$, large bumps 
with a $0.1 \mathrm{~nm}$ corrugation were arranged in a regular lattice with a $1.8 \mathrm{~nm}$ consistent with the $(6 \times 6)$ quasi-cell indicated by the sky blue rhomb. The green cell with a $3.2 \mathrm{~nm}$ length appeared to be very similar to the STM images of $6 \mathrm{H}$ $\operatorname{SiC}(0001)(6 \sqrt{3} \times 6 \sqrt{3})$ R30 reconstructed surface obtained with W or Pt tips [48-51]. A lattice with a smaller period could also be observed, as shown in Fig. 5b. This image confirmed the presence of an epitaxial layer of graphene on the reconstructed SiC surface; the honeycomb lattice, highlighted by the blue hexagon, was clearly imaged. We pointed out that there is no distinctive feature between this STM image (Fig. 5b) obtained with a CF tip and STM images obtained with W or Pt/Ir tips [52,53].

Working with an oscillating tip in STM mode with a $\mathrm{Z}$ regulation based on the mean-tunneling-current, $\left\langle\mathrm{I}_{\mathrm{T}}\right\rangle$, gave both the dynamic STM image and simultaneously the map of force gradient that was developed between the tip and the surface. Fig. $6 \mathrm{a}$ shows the reconstructed $\mathrm{SiC}(0001)$ surface, with a measured corrugation amplitude of $0.2 \mathrm{~nm}$. This topography corresponds well to the $(6 \sqrt{3} \times 6 \sqrt{3}) \mathrm{R} 30^{\circ}$ reconstruction lattice of the $6 \mathrm{H}-\mathrm{SiC}(0001)$ surface (green rhomb unit cell), obtained with the non-oscillating CF tips (Fig. 5a) while the sky blue cell corresponds to the $(6 \times 6)$ quasi-cell. The corresponding map of the frequency shift variations (Fig. 6b) displayed modulations in which some periodic arrangements of protrusions could be detected. Actually, this map presented the same lattice as the dynamic STM image as showed out by the fast Fourier transform diagram.

Because the oscillation amplitude of the tip probe was smaller than one ångström the variations of the force gradient could be easily deduced from the frequency shift [17]. With modulations of the frequency shift ranging from 16 to $32 \mathrm{~Hz}$ variations in force gradient between the tip and the surface were found to vary from $8.25 \mathrm{~N} / \mathrm{m}$ to $16.50 \mathrm{~N} / \mathrm{m}$ when using the Eq. (28) of [17] (Fig. 6b). Therefore, the tip suffered changes of the force gradient by a factor 2 during the

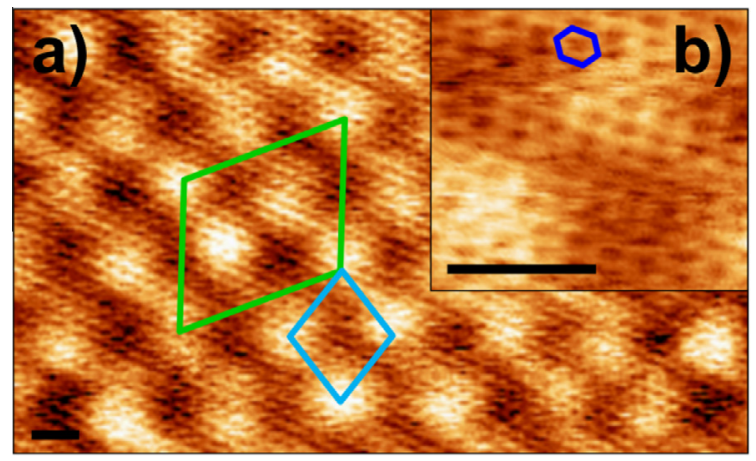

Fig. 5 - Typical constant current STM image of a $6 \mathrm{H}-$ $\operatorname{SiC}(0001)(6 \sqrt{3} \times 6 \sqrt{3}) \mathrm{R}^{\circ} 0^{\circ}$ reconstructed surface covered by a single layer of epitaxial graphene obtained with a non oscillating CF tip (green cell); $I_{T}=300 p A, V_{T}=-50 \mathrm{mV}$ and $\mathrm{Z}$ range $0.1 \mathrm{~nm}$. In the insert, the atomic resolution is achieved as shown by the blue hexagon high lightening the cell between the centers of neighboring graphene cells $\left(I_{T}=600 \mathrm{pA}, \mathrm{V}_{\mathrm{T}}=-50 \mathrm{mV}, \mathrm{Z}\right.$ range $\left.=0.1 \mathrm{~nm}\right)$. Black scale bar for both images, $1 \mathrm{~nm}$. (A color version of this figure can be viewed online.)
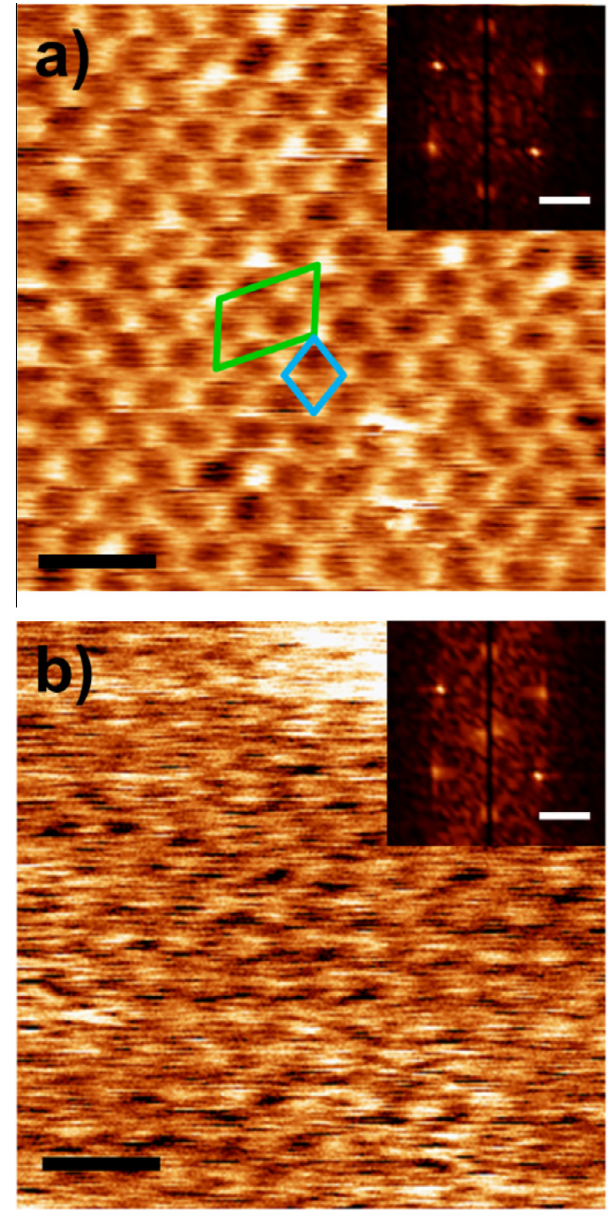

Fig. 6 - Typical constant mean-tunneling-current images obtained in dynamic STM mode of an epitaxial graphene covering a $6 \mathrm{H}-\mathrm{SiC}(0001)(6 \sqrt{3} \times 6 \sqrt{3}) \mathrm{R} 30^{\circ}$ reconstructed surface; (a) shows the topography and (b) the map of force gradient ranging from 16 to $32 \mathrm{~Hz}(8.25-16.50) \mathrm{N} / \mathrm{m}$ (black scale bar, $4 \mathrm{~nm}$ ). In inset, the fast Fourier transform demonstrates the presence of the hexagonal lattice of the reconstruction (white scale bar, $\left.0.5(1 / \mathrm{nm})) .<\mathrm{I}_{\mathrm{T}}\right\rangle=20 \mathrm{pA}$, $V_{T}=-300 \mathrm{mV}$, oscillation amplitude $=0.07 \mathrm{~nm}$. (A color version of this figure can be viewed online.)

scanning of the epitaxial graphene on the reconstructed $\mathrm{SiC}(0001)$ surface in dynamic STM mode under a relatively low constant mean-tunneling-current and a bias voltage of $-300 \mathrm{mV}$.

Because different CF tips were used for the study of the reconstructed $\mathrm{SiC}(0001)$ surfaces, partially covered by epitaxial graphene, and all of them gave the same kind of STM images of the reconstruction structure, we concluded that our fabrication protocol of CF tips is reproducible. However, atomic resolution on graphene in dynamic STM mode could not be achieved despite several attempts. A possible reason could be the low and non-constant LDOS of the CF tip. Consequently, the tip must be in repulsive interaction with EG. In this case, the stability of the tip/surface junction depends on the mechanical properties of the electrochemically etched CF tip which are weak because the structure of CF consists of an amorphous core surrounded by a skin enriched by 


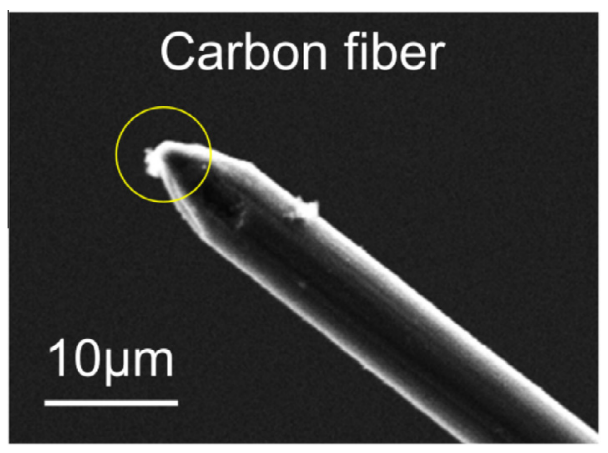

Fig. 7 - Apex of the carbon fiber tip brooked after of a surface scanning over step edges of epitaxial graphene on $6 \mathrm{H}-$ $\mathrm{SiC}(0001)$ in dynamic STM and AFM modes. (A color version of this figure can be viewed online.)

graphitic domains [54]. High mechanical stress applied during high resolution investigations in the oscillating mode, or when the tip scanned over steep step edges would destroy the sharp apex of the tip while the scanning of the hard SiC surface. SEM observations of some tips used for dynamic STM investigation support this hypothesis (Fig. 7). From DFT simulations of STM images, Dappe et al. [37] found that a graphitic tip suffers strong mechanical deformation during scanning a graphene layer at small tip/surface distance, which is the case of the repulsive tip/surface interaction in Fig. 6. One way to improve the mechanical properties of these $\mathrm{CF}$ tips could be to favor the carbon crystallization of the fiber core by a high temperature annealing in UHV, or to use a tip ending by a carbon nanotube as in a recent study [36].

\section{Conclusion}

In this work, ultra-sharp tips used for combined STM/AFM experiments were prepared from carbon fiber. Then they were characterized using SEM, Fowler-Nordheim plots, and STM images of epitaxial graphene supported on SiC surfaces. CFs were electrochemically etched in $\mathrm{NaOH} / \mathrm{KOH}$ electrolytes under different conditions. With the use of a method that controlled the etching current intensity, CF tips with apex radii $\sim 10 \mathrm{~nm}$ could reproducibly be obtained as deduced from Fowler-Nordheim plots. In these conditions, STM and dynamic STM images were easily obtained without using a UHV tip cleaning procedure. Fig. 5 and Fig. 6 clearly show the lattice with a $3.3 \mathrm{~nm}$ period of the $(6 \sqrt{3} \times 6 \sqrt{3}) \mathrm{R} 30^{\circ}$ reconstructed $\mathrm{SiC}(0001)$ surface covered by an epitaxial graphene layer similar to those recorded with clean Pt/Ir or W tips. The map of force gradient simultaneously recorded with the constant mean current and the dynamic STM image revealed that variations of tip/surface force gradient occur during the scanning process. We are working on the improvement of the mechanical properties of these tips which could control the atomic resolution on graphene. Besides studies of material surfaces in UHV, such CF tips which are chemically inert and conductive open ways for nanometric AFM explorations with simultaneous electric measurements as Kelvin Probe Force Microscopy in air or in liquid, particularly for biology.

\section{Acknowledgments}

We wish to thank M. Mayne-L'Hermitte and M. Pinault (CEA/ IRAMIS/NIMBE/LEDNA) for providing the CFs, A. Ouerghi ((CNRS-LPN), Route de Nozay, 91460 Marcoussis, France) for the preparation of epitaxial graphene on $6 \mathrm{H}-\mathrm{SiC}(0001)$ samples, L. Pham Van (CEA/IRAMIS/SPEC/LEPO) for discussions on tip etching process and S. Foucquart (CEA/IRAMIS/NIM$\mathrm{BE} / \mathrm{LIONS}$ ) for his technical assistance. We also would like to thank Y. Dappe and S. Latil (CEA/IRAMIS/SPEC/GMT) for fruitful discussions on the electronic properties of graphene layers.

José Antonio Morán Meza would also like to acknowledge financial support from the Peru's National Council of Science and Technology (Concytec), the Réseau Thématique de Recherche Avancée (RTRA-Triangle de la Physique), and the CEA/Direction des Relations Internationales (DRI).

\section{Appendix}

Attached onto the oscillating prong of a qPlus probe, the CF tip can present resonance eigenvalues coupled to the quartz vibration with the consequence of troublesome tip vibrations that induce a lower lateral resolution during the STM imaging process. Therefore we estimated the length of a cylindrical wire with a resonance frequency equal to $30 \mathrm{kHz}$ from the following equation. The vibration of a cylinder attached by one end is given by [55]:

$f=\frac{R}{2 \pi l^{2}}\left(\frac{\pi E}{\rho}\right)^{1 / 2}$

where $f$ is the frequency at which the fiber vibrates $(\mathrm{Hz}), l$ the length $(\mathrm{m})$ of the fiber, $E$ the Young's modulus of the carbon fiber ( $500 \mathrm{GPa}), \rho$ the CF density $\left(2000 \mathrm{~kg} / \mathrm{m}^{3}\right)$ and $R$ the fiber radius $(3.35 \mu \mathrm{m})$ [54]. We found that CFs with a length equal to $0.5 \mathrm{~mm}$ and $0.7 \mathrm{~mm}$ exhibit a resonance frequency at $59.8 \mathrm{kHz}$ and $30.5 \mathrm{kHz}$ respectively. So, we pay attention that the length of the CF tip glued on the tuning fork was shorter than $0.5 \mathrm{~mm}$ for our STM investigations. Attached to the end of the free prong of a qPlus probe glued to an Omicron tripod, a $\sim 0.4 \mathrm{~mm}$ length CF provokes some changes in the oscillating behavior of the tuning fork. Typically the resonance frequency shifts down by less than $100 \mathrm{~Hz}$ when compared to a qPlus oscillating in air without CF. We notice that this frequency shift is smaller than the ones resulting in the Pt/Ir tip fixation because the resonance frequency falls down by typically $\sim 1 \mathrm{kHz}$. This advantage of CF tips was previously pointed out par Castellanos et al. [32].

\section{R E F E R E N C E S}

[1] Binnig G, Quate CF, Gerber C. Atomic force microscope. Phys Rev Lett 1986;56(9):930-4. http://dx.doi.org/10.1103/ PhysRevLett. 56.930 .

[2] Binnig G, Rohrer H. Scanning tunneling microscopy. Helv Phys Acta 1982;55:726-35. http://dx.doi.org/10.5169/seals$\underline{115309 .}$. 
[3] Melmed AJ. The art and science and other aspects of making sharp tips. J Vac Sci Technol B 1991;9(2):601-8. http:// dx.doi.org/10.1116/1.585467.

[4] Morikawa H, Goto K. Reproducible sharp-pointed tip preparation for field ion microscopy by controlled ac polishing. Rev Sci Instrum 1988;59(10):2195-7. http:// dx.doi.org/10.1063/1.1139985.

[5] Fotino M. Tip sharpening by normal and reverse electrochemical etching. Rev Sci Instrum 1993;64(1):159-67. http://dx.doi.org/10.1063/1.1144419.

[6] Ibe JP. On the electrochemical etching of tips for scanning tunneling microscopy. J Vac Sci Technol A 1990;8(4):3570-5. http://dx.doi.org/10.1116/1.576509.

[7] Libiouille L, Houbion Y, Gilles J-M. Very sharp platinum tips for scanning tunneling microscopy. Rev Sci Instrum 1995;66(1):97-100. http://dx.doi.org/10.1063/1.1146153.

[8] Klein M, Schwitzgebel G. An improved lamellae drop-off technique for sharp tip preparation in scanning tunneling microscopy. Rev Sci Instrum 1997;68(8):3099-103. http:// dx.doi.org/10.1063/1.1148249.

[9] Lindahl J, Takanen T, Montelius L. Easy and reproducible method for making sharp tips of Pt/Ir. J Vac Sci Technol B 1998;16(6):3077-81. http://dx.doi.org/10.1116/1.590445.

[10] Sørensen AH, Hvid U, Mortensen MW, Mørch KA. Preparation of platinum-iridium scanning probe microscopy tips. Rev Sci Instrum 1999;70(7):3059-67. http://dx.doi.org/10.1063/ 1.1149891.

[11] Nakamura Y, Mera Y, Maeda K. A reproducible method to fabricate atomically sharp tips for scanning tunneling microscopy. Rev Sci Instrum 1999;70(8):3373-6. http:// dx.doi.org/10.1063/1.1149921.

[12] Ju B-F, Chen Y-L, Fu M, Chen Y, Yang Y. Systematic study of electropolishing technique for improving the quality and production reproducibility of tungsten STM probe. Sens Actuators A Phys 2009;155:136-44. http://dx.doi.org/10.1016/ j.sna.2009.08.013.

[13] Hagedorn T, El Ouali M, Paul W, Oliver D, Miyahara Y, Grütter P. Refined tip preparation by electrochemical etching and ultrahigh vacuum treatment to obtain atomically sharp tips for scanning tunneling microscope and atomic force microscope. Rev Sci Instrum 2011;82. http://dx.doi.org/ 10.1063/1.3660279 [113903/5pp].

[14] Karrai K, Grober RD. Piezo-electric tuning fork tip-sample distance control for near field optical microscopes. Ultramicroscopy 1995;61:197-205. http://dx.doi.org/10.1016/ 0304-3991(95)00104-2.

[15] Edwards H, Taylor L, Duncan W, Melmed AJ. Fast, highresolution atomic force microscopy using a quartz tuning fork as actuator and sensor. J Appl Phys 1997;82(3):980-4. http://dx.doi.org/10.1063/1.365936.

[16] Giessibl FJ. High-speed force sensor for force microscopy and profilometry utilizing a quartz tuning fork. Appl Phys Lett 1998;73(26):3956-8. http://dx.doi.org/10.1063/1.122948.

[17] Giessibl FJ. Advances in atomic force microscopy. Rev Mod Phys 2003;75(3):949-83. http://dx.doi.org/10.1103/ RevModPhys. 75.949.

[18] Hembacher S, Giessibl F, Mannhart J, Quate C. Local spectroscopy and atomic imaging of tunneling current, forces, and dissipation on graphite. Phys Rev Lett 2005;94. http://dx.doi.org/10.1103/PhysRevLett. 94.056101 [056101/ 4pp].

[19] Polesel-Maris J, Lubin C, Thoyer F, Cousty J. Combined dynamic scanning tunneling microscopy and frequency modulation atomic force microscopy investigations on polythiophene chains on graphite with a tuning fork sensor. J Appl Phys 2011;109. http://dx.doi.org/10.1063/1.3556437 [074320/10pp]
[20] Ng BP, Zhang Y, Wei Kok S, Chai Soh Y. Improve performance of scanning probe microscopy by balancing tuning fork prongs. Ultramicroscopy 2009;109:291-5. http://dx.doi.org/ 10.1016/j.ultramic.2008.11.029.

[21] Torbrügge S, Schaff O, Rychen J. Application of the KolibriSensor ${ }^{\circledR}$ to combined atomic-resolution scanning tunneling microscopy and noncontact atomic-force microscopy imaging. J Vac Sci Technol B 2010;28(3):12-20. http://dx.doi.org/10.1116/1.3430544.

[22] Fujii T. Micropattern measurement with an atomic force microscope. J Vac Sci Technol B 1991;9(2):666-9. http:// dx.doi.org/10.1116/1.585483.

[23] Radmacher M, Tillamnn RW, Fritz M, Gaub HE. From molecules to cells: imaging soft samples with the atomic force microscope. Science 1992;257:1900-5. http://dx.doi.org/ 10.1126/science.1411505.

[24] Nguyen CV, Chao K, Stevens RMD, Delzeit L, Cassell A, Han J, et al. Carbon nanotube tip probes : stability and lateral resolution in scanning probe microscopy and application to surface. Nanotechnology 2001;12:363-7. http://dx.doi.org/ 10.1088/0957-4484/12/3/326.

[25] Zhao M, Sharma V, Wei H, Birge RR, Stuart JA, Papadimitrakopoulos F, et al. Ultrasharp and high aspect ratio carbon nanotube atomic force microscopy probes for enhanced surface potential imaging. Nanotechnology 2008;19. http://dx.doi.org/10.1088/0957-4484/19/23/235704 [235704/7pp]

[26] Buchoux J, Aimé J-P, Boisgard R, Nguyen CV, Buchaillot L, Marsaudon S. Investigation of the carbon nanotube AFM tip contacts: free sliding versus pinned contact. Nanotechnology 2009;20. http://dx.doi.org/10.1088/0957-4484/20/47/475701 [475701/8pp]

[27] Wilson NR, Macpherson JV. Carbon nanotube tips for atomic force microscopy. Nat Nanotechnol 2009;4:483-91. http:// dx.doi.org/10.1038/nnano.2009.154.

[28] Armstrong-James M, Fox K, Millar J. A method for etching the tips of carbon fibre microelectrodes. J Neurosci Methods 1980;2:431-2. http://dx.doi.org/10.1016/0165-0270(80)90009-6.

[29] Mousa MS. Electron emission from carbon fibre tips. Appl Surf Sci 1996;94-95:129-35. http://dx.doi.org/10.1016/01694332(95)00521-8.

[30] Schulte A, Chow RH. Cylindrically etched carbon-fiber microelectrodes for low-noise amperometric recording of cellular secretion. Anal Chem 1998;70(5):985-90. http:// dx.doi.org/10.1021/ac970934e.

[31] Chen S, Kucernak A. Fabrication of carbon microelectrodes with an effective radius of $1 \mathrm{~nm}$ Electrochem Commun 2002;4:80-5. http://dx.doi.org/ 10.1016/S1388-2481(01)00278-8.

[32] Castellanos-Gomez A, Agraït N, Rubio-Bollinger G. Carbon fibre tips for scanning probe microscopy based on quartz tuning fork force sensors. Nanotechnology 2010;21. http:// dx.doi.org/10.1088/0957-4484/21/14/145702 [145702/9pp].

[33] Sripirom J, Noor S, Köhler U, Schulte A. Easily made and handled carbon nanocones for scanning tunneling microscopy and electroanalysis. Carbon N Y 2011;49:2402-12. http://dx.doi.org/10.1016/j.carbon.2011.02.007.

[34] Rubio-Bollinger G, Castellanos-Gomez A, Bilan S, Zotti LA, Arroyo CR, Agraït N, et al. Carbon-fiber tips for scanning probe microscopes and molecular electronics experiments. Nanoscale Res Lett 2012;7. http://dx.doi.org/10.1186/1556276X-7-254 [254/4pp].

[35] Castellanos-gomez A, Agraït N, Rubio-bollinger G. Characterization and optimization of quartz tuning fork based force sensors for combined STM/AFM. Scanning Probe Microsc Nanosci Nanotechnol 2013;3:23-53. http://dx.doi.org/ 10.1007/978-3-642-25414-7_ 2 . 
[36] Kim J, Huang J, de Lozanne A. Honeycomb lattice of graphite probed by scanning tunneling microscopy with a carbon nanotube tip. Mesoscale Nanoscale Phys 2013:1-11. http:// arxiv.org/ftp/arxiv/papers/1303/1303.0319.pdf.

[37] Dappe YJ, González C, Cuevas JC. Carbon tips for all-carbon single-molecule electronics. Nanoscale 2014;6:6953-8. http:// dx.doi.org/10.1039/c4nr00516c.

[38] Fowler RH, Nordheim L. Electron emission in intense electric fields. Proc R Soc Lond A 1928;119:173-81. http://dx.doi.org/ 10.1098/rspa.1928.0091.

[39] Wang MS, Wang JY, Peng L-M. Engineering the cap structure of individual carbon nanotubes and corresponding electron field emission characteristics. Appl Phys Lett 2006;88:243108. http://dx.doi.org/10.1063/1.2208941.

[40] Spindt CA, Brodie I, Humphrey L, Westerberg ER. Physical properties of thinfilm field emission cathodes with molybdenum cones. J Appl Phys 1976;47:5248-63. http:// dx.doi.org/10.1063/1.322600.

[41] Dyke WP, Dolan WW. Field emission. Adv Electron Electron Phys 1956;8:89-185. http://dx.doi.org/10.1016/S00652539(08)61226-3.

[42] Gomer R. Field emission and field ionization. Cambridge, Mass: Harvard University Press; 1961.

[43] Lucier A-S, Mortensen H, Sun Y, Grütter P. Determination of the atomic structure of scanning probe microscopy tungsten tips by field ion microscopy. Phys Rev B 2005;72. http:// dx.doi.org/10.1103/PhysRevB.72.235420 [235420/9pp].

[44] Lucier A. Preparation and characterization of tungsten tips suitable for molecular electronics studies. 2004, http://www. physics.mcgill.ca/ peter/theses/lucier.pdf.

[45] Shiraishi M, Ata M. Work function of carbon nanotubes. Carbon N Y 2001;39:1913-7. http://dx.doi.org/10.1016/S00086223(00)00322-5.

[46] Müller EW. Work function of tungsten single crystal planes measured by the field emission microscope. J Appl Phys 1955;26(6):732-7. http://dx.doi.org/10.1063/1.1722081.
[47] Horcas I, Fernández R, Gómez-Rodríguez JM, Colchero J, Gómez-Herrero J, Baro AM. WSXM: A software for scanning probe microscopy and a tool for nanotechnology. Rev Sci Instrum 2007;78. http://dx.doi.org/10.1063/1.2432410 [013705/ 8pp].

[48] Penuelas J, Ouerghi A, Lucot D, David C, Gierak J. Surface morphology and characterization of thin graphene films on SiC vicinal substrate. Phys Rev B 2009;79. http://dx.doi.org/ 10.1103/PhysRevB.79.033408 [033408/4pp].

[49] Varchon F, Mallet P, Veuillen J-Y, Magaud L. Ripples in epitaxial graphene on the Si-terminated $\mathrm{SiC}(0001)$ surface. Phys Rev B 2008;77. http://dx.doi.org/10.1103/ PhysRevB.77.235412 [235412/8pp].

[50] Starke U, Riedl C. Epitaxial graphene on SiC (0001) and SiC $(000-1)$ : from surface reconstructions to carbon electronics. J Phys Condens Matter 2009;21. http://dx.doi.org/10.1088/ 0953-8984/21/13/134016 [134016/12pp].

[51] Ouerghi A, Silly MG, Marangolo M, Mathieu C, Eddrief M, Picher $\mathrm{M}$, et al. Large-area and high-quality epitaxial graphene on off-axis SiC wafers. ACS Nano 2012;6(7):6075-82. http://dx.doi.org/10.1021/nn301152p.

[52] Goler S, Coletti C, Piazza V, Pingue P, Colangelo F, Pellegrini V, et al. Revealing the atomic structure of the buffer layer between $\mathrm{SiC}(0001)$ and epitaxial graphene. Carbon N Y 2013;51:249-54. http://dx.doi.org/10.1016/ j.carbon.2012.08.050.

[53] Lauffer P, Emtsev KV, Graupner R, Seyller T, Ley L. Atomic and electronic structure of few-layer graphene on $\mathrm{SiC}(0001)$ studied with scanning tunneling microscopy and spectroscopy. Phys Rev B 2008;77. http://dx.doi.org/10.1103/ PhysRevB.77.155426 [155426/10pp].

[54] Edie DD. The effect of processing on the structure and properties of carbon fibers. Carbon N Y 1998;36(4):345-62. http://dx.doi.org/10.1016/S0008-6223(97)00185-1.

[55] Duvaut G. Mécanique des milieux continus. Dunot; 1990. 